\title{
Binding of $\alpha_{v} \beta_{3}$ Integrin-Specific Radiotracers Is Modulated by Both Integrin Expression Level and Activation Status
}

\author{
Alexandra Andriu, ${ }^{1}$ Julie Crockett, ${ }^{2}$ Sergio Dall'Angelo, ${ }^{3}$ Monica Piras, ${ }^{3}$ Matteo Zanda, ${ }^{3}$ \\ lan N. Fleming (1) ${ }^{1}$ \\ ${ }^{1}$ Aberdeen Biomedical Imaging Centre, Institute of Medical Sciences, University of Aberdeen, Aberdeen, AB25 2ZD, UK \\ ${ }^{2}$ Arthritis and Musculoskeletal Medicine Research Programme, Division of Applied Medicine, Institute of Medical Sciences, University of \\ Aberdeen, Aberdeen, AB25 2ZD, UK \\ ${ }^{3}$ Kosterlitz Centre for Therapeutics, Institute of Medical Sciences, University of Aberdeen, Aberdeen, Scotland, AB25 2ZD, UK
}

\begin{abstract}
Purpose: Molecular imaging of $\alpha_{v} \beta_{3}$ integrin has exhibited real potential to guide the appropriate use of anti-angiogenic therapies. However, an incomplete understanding of the factors that influence binding of $\alpha_{v} \beta_{3}$ integrin-specific radiotracers currently limits their use for assessing response to therapy in cancer patients. This study identifies two fundamental factors that modulate uptake of these radiotracers.

Procedures

Experiments were performed in prostate cancer (PC3) and glioblastoma (U87MG) cells, which differentially express $\alpha_{v} \beta_{3}$ integrin. $\alpha_{v} \beta_{3}$ integrin-specific radiotracers were used to investigate the effect of manipulating $\alpha_{\mathrm{v}} \beta_{3}$ integrin expression or activation in cellular binding assays. $\beta_{3}$ integrin and $\alpha_{v} \beta_{3}$ integrin expression were measured by western blotting and flow cytometry, respectively. The effect of select pharmacological inhibitors on $\alpha_{v} \beta_{3}$ integrin activation and expression was also determined.

Results: Radiotracer binding was proportional to $\alpha_{v} \beta_{3}$ integrin expression when it was decreased ( $\beta_{3}$ knock-down cells) or increased, either using pharmacological inhibitors of cell signalling or by culturing cells for different times. Studies with both small molecule and arginine-glycineaspartic acid (RGD)-based radiotracers revealed increased radiotracer binding after activation of $\alpha_{v} \beta_{3}$ integrin with $\mathrm{Mn}^{2+}$ or talin head domain. Moreover, inhibition of fundamental signalling pathways (mitogen-activated protein kinase kinase (MEK), Src and VEGFR2) decreased radiotracer binding, reflecting reduced $\alpha_{v} \beta_{3}$ integrin activity.

Conclusion: Binding of small molecule ligands and radiolabelled RGD peptides is modulated by expression and activation status of $\alpha_{v} \beta_{3}$ integrin. $\alpha_{v} \beta_{3}$ integrin-specific radiotracers can provide otherwise inaccessible information of the effect of signalling pathways on $\alpha_{v} \beta_{3}$ integrin. This has significant implications for assessing response to anti-angiogenic therapies in clinical studies.
\end{abstract}

Key words: Tumour angiogenesis, $\alpha_{v} \beta_{3}$ integrin, Integrin signalling, Response assessment, PET imaging, Radiolabelled RGD peptides

Electronic supplementary material The online version of this article (doi:10.1007/s11307-017-1100-z) contains supplementary material, which is available to authorized users.

Correspondence to: Ian Fleming; e-mail: i.n.fleming@abdn.ac.uk 


\begin{abstract}
Abbreviations: cRGDfK, Cyclo(Arg-Gly-Asp-D-Phe-Lys) peptide; ERK, Extracellular signal regulated kinase; GFP, Green fluorescent protein; FAK, Focal adhesion kinase; MEK, Mitogen-activated protein kinase kinase; MIDAS, Metal ion-dependent adhesion site; PC, Prostate cancer; PET, Positron emission tomography; THD, Talin head domain; VEGF, Vascular endothelial factor; VEGFR2, Vascular endothelial factor receptor 2
\end{abstract}

\section{Introduction}

Tumour angiogenesis, the formation of new blood vessels, is a hallmark of cancers that allows them to grow beyond a critical size $(2-3 \mathrm{~mm})$ and metastatize to other organs [1]. The angiogenic switch is triggered by tumour growth which creates a hypoxic and acidic environment, promoting release of proangiogenic factors such as vascular endothelial growth factor (VEGF) and development of new blood vessels and endothelial cell migration via integrins [1]. Therapeutic interventions that target VEGF receptor 2 (VEGFR2) and integrins have been evaluated as anti-angiogenic treatments, in accordance with their key roles in the pathogenesis of tumour angiogenesis [2, 3]. However, effective imaging methods are needed to assess whether tumours are actually responding to therapy, as the efficacy of these treatments varies considerably between tumour types and individual cancer patients.

The integrin family comprises 24 transmembrane receptors formed by heterodimeric combinations of $18 \alpha$ and $8 \beta$ subunits. Each subunit comprises a short cytoplasmic domain, a single transmembrane region and an extracellular domain. Ligand binding to the extracellular domain allows integrins to collate information about the extracellular environment $[4,5]$. In addition, their cytoplasmic domains recruit intracellular proteins such as talin, focal adhesion kinase (FAK) and Src, leading to activation of canonical signalling pathways. As a result of these interactions, integrins change their conformation (i.e., undergo activation or inactivation) thereby driving tumour angiogenesis [6, 7].

Molecular imaging of $\alpha_{v} \beta_{3}$ integrin offers a specific and quantitative method of assessing the angiogenic potential of tumours [8]. $\alpha_{\mathrm{v}} \beta_{3}$ integrin is highly expressed on angiogenic endothelial cells, involved in cell adhesion [9], cell migration and metastasis [2] and is a validated target for assessing tumour angiogenesis [10]. Vitronectin and fibronectin bind selectively to this receptor through an arginine-glycineaspartic acid (RGD) recognition sequence. Multiple positron emission tomography (PET) radiotracers have been designed based on the RGD motif to provide information on tumour vasculature, with $\left[{ }^{18} \mathrm{~F}\right] \mathrm{Galacto}-\mathrm{RGD}$ [11] and $\left[{ }^{18} \mathrm{~F}\right]$ Fluciclatide [12] being the best characterised.

Clinical studies [11-13] and mouse xenograft experiments $[14,15]$ have both observed correlation between $\alpha_{\mathrm{v}} \beta_{3}$ integrin radiotracer uptake and baseline $\alpha_{\mathrm{v}} \beta_{3}$ integrin expression, supporting the use of these radiotracers as surrogate markers of tumour angiogenic potential. Clinical studies have not yet endorsed these radiotracers for assessing response to therapy, despite their considerable potential in this role [16]. One key reason is our incomplete understanding of how molecular mechanisms influence radiotracer uptake; two preclinical studies that have compared radiotracer binding with $\alpha_{\mathrm{v}} \beta_{3}$ integrin expression after anti-angiogenic therapy observed changes in radiotracer binding that could not be attributed to altered $\alpha_{v} \beta_{3}$ expression $[17,18]$. These reports strongly suggest that there are uncharacterised factor(s) that can influence binding of these radiotracers to cells/tumours.

In this study, we present conclusive evidence that binding of $\alpha_{\mathrm{v}} \beta_{3}$ integrin radiotracers to cells is influenced by both the expression level and activation status of the target receptor. Moreover, we also demonstrate that inhibition of fundamental signalling pathways (mitogen-activated protein kinase kinase (MEK), Src and VEGFR2) influences $\alpha_{v} \beta_{3}$ integrin radiotracer binding, resulting from a change in integrin expression or reflecting decreased binding affinity. These results broaden our understanding of the molecular changes caused by anti-angiogenic treatment and have significant implications for the use of $\alpha_{v} \beta_{3}$ integrin-specific radiotracers in assessing response to therapy with these agents.

\section{Materials and Methods}

\section{Reagents}

All reagents were purchased from Sigma-Aldrich, unless stated otherwise. UO126, PP-2, PF573228 and ZM323881 were from Bio-Techne. JetPRIME® transfection reagent was from Source BioScience. Talin head domain (THD) construct [19] was a kind gift from Prof David A. Calderwood (Yale University, USA). Anti- $\alpha_{v} \beta_{3}$ integrin MAB1976 (LM609) was from Merck Millipore.

\section{Cell Lines and Culture Conditions}

All cell lines used in this study (prostate cancer (PC) 3 and U87MG) were authentic and purchased from ATCC. These cell lines were specifically selected because they are known to express moderate and high levels of $\alpha_{\mathrm{v}} \beta_{3}$, respectively. Cells were cultured in RPMI medium supplemented with $10 \%$ FCS and 100 units $/ \mathrm{ml}$ penicillin and $100 \mu \mathrm{g} / \mathrm{ml}$ streptomycin under sterile conditions at $37{ }^{\circ} \mathrm{C}$ in a humidified atmosphere containing $5 \% \mathrm{CO}_{2}$. 


\section{Western Blotting}

PC3 and U87MG cells were seeded at $0.35 \times 10^{6}$ cells $/ 60 \mathrm{~mm}$ plate. On the next day, cells were incubated with the specified concentrations of UO126, ZM323881, PF573228 or PP2 for the time indicated in each experiment. Cells were then washed with PBS and scraped into lysis buffer (PBS containing $1 \mathrm{mM}$ sodium orthovanadate, $1 \mathrm{mM}$ sodium pyrophosphate, dithiothreitol and protease inhibitors) and lysed by sonication. The total cell lysate was used to ensure that all blots are fully representative of the total cellular expression of each protein. The protein concentration in each sample was determined using the bicinchoninic acid (BCA) assay. Western blotting was performed essentially using the method indicated previously [20] with minor modifications using primary antibodies against the following proteins: $\beta_{3}$ integrin, Santa Cruz Biotechnology; extracellular signal regulated kinase (ERK)1 and 2, pThr ${ }^{202} / \mathrm{Tyr}^{204}$ ERK 1 and 2, VEGFR2, pTyr $^{175}$ VEGFR2, FAK, pTyr ${ }^{397}$ FAK, Src and $\mathrm{pTyr}^{416}$ Src all from Cell Signalling; and green fluorescent protein (GFP) MAB3580 from EMD Merck Millipore. After incubation with primary antibody, membranes were washed in PBS containing $0.1 \%$ Tween 20 , then incubated for $1 \mathrm{~h}$ with the appropriate IR dye-conjugated secondary antibody (LI-COR) diluted 1:10,000. Images were captured with an Odyssey ${ }^{\circledR}$ CLx LI-COR imaging system. The densitometry of each protein band was measured using Image Studio Lite.

\section{Flow Cytometry Analysis of $\alpha_{v} \beta_{3}$ Integrin Expression}

PC3 and U87MG cells were seeded at $0.35 \times 10^{6}$ cells $/ 60 \mathrm{~mm}$ plate and grown for $72 \mathrm{~h}$ before the experiment, unless stated otherwise. Cells were harvested from plates using cell dissociation reagent. $\alpha_{v} \beta_{3}$ cell surface expression was determined by flow cytometry as previously described [21], using the LM609 antibody which binds selectively to $\alpha_{v} \beta_{3}$ integrin and detected with an Alexa Fluor 488 secondary antibody. Data were normalised against the untreated control, unless otherwise stated.

\section{In Vitro Radiotracer Binding Assay}

ZMPZAT71 is a novel triazole-based $\alpha_{v} \beta_{3}$ selective radiotracer with high $\alpha_{v} \beta_{3}$ binding affinity designed at the University of Aberdeen [22]. Experiments were either performed with $\left[{ }^{3} \mathrm{H}\right] Z$ ZMPZAT71 (synthesised by RC TRITEC Ltd., Switzerland) or with $\left[{ }^{18} \mathrm{~F}\right]$ FDR-Aoac(RGDfK) [21]. Cells were seeded at $0.35 \times 10^{6}$ cells/ $60 \mathrm{~mm}$ plate and grown for $72 \mathrm{~h}$, unless stated otherwise. On the day of the experiment, medium in each plate was replaced with $3 \mathrm{ml}$ fresh RPMI containing $0.1 \%$ BSA. $\left[{ }^{3} \mathrm{H}\right] \mathrm{ZMPZAT} 71$ was added at $0.5 \mathrm{MBq} / \mathrm{plate}$ and incubated for $30 \mathrm{~min}$ (maximum radiotracer binding occurred within $30 \mathrm{~min}$; data not shown). Unbound radioactivity was removed by rinsing the plates five times with ice-cold PBS. Cells were detached using $0.35 \mathrm{ml}$ trypsin and neutralised with $0.35 \mathrm{ml}$ RPMI. The radioactivity present in $0.5 \mathrm{ml}$ cell suspension was measured in a TRICARB 2100 TR scintillation counter using ultima gold scintillation fluid. The protein content in the remaining $0.2 \mathrm{ml}$ was measured using the BCA assay. Binding was expressed as a function of radioactivity added per plate and normalised to protein content. Radiotracer binding was performed in the presence and absence of $10 \mu \mathrm{M}$ Cyclo(Arg-Gly-Asp-D-PheLys) peptide (cRGDfK) (a non-radiolabelled cyclic peptide known to bind selectively to $\alpha_{v} \beta_{3}$ integrin) [21]. Binding in the absence of cRGDfK represents total binding. Binding in presence of cRGDfK signifies non-specific binding. The difference between total and non-specific binding denotes specific binding (Fig. S1).

\section{$\beta_{3}$ Integrin Knock-Down Clones}

U87MG cells with decreased $\alpha_{v} \beta_{3}$ integrin expression were generated by transfecting cells with a small hairpin RNA (shRNA) vector that specifically targets the integrin $\beta_{3}$ subunit (GeneCopoeia, Rockville, USA). Cells that stably incorporated the shRNA vector were selected using puromycin. Individual cells were selected and allowed to proliferate prior to analysis for $\beta_{3}$ knock-down by western blot and flow cytometry.

\section{Talin Head Domain Transfection}

U87MG and PC3 cells were seeded at $0.35 \times 10^{6}$ cells per $60 \mathrm{~mm}$ plate and incubated overnight. Cells were then transfected with either a THD construct linked to GFP or mock transfected, using JetPRIME reagent according to manufacturer's instructions. Transfection efficiency in both cell lines was optimised by measuring the number of green cells at various times (4-48 h) after THD-GFP transfection using an EVOS AMG fluorescence digital inverted microscope.

\section{Statistical Analysis}

Microsoft Office Excel 2013 for Windows and GraphPad Prism 5 were used for data processing, graph plotting and statistical analysis. Statistical analysis of all data was performed using two-tailed Student's $t$ test for two groups or one-way analysis of variance (ANOVA) for three or more groups. $P$ values less than 0.05 were considered statistically significant.

\section{Results}

\section{Radiotracer Binding Reflects $\alpha_{v} \beta_{3}$ Expression Level}

In U87MG cells, we observed that total $\beta_{3}$ integrin expression varied with cultivation time (Fig. 1a), more than doubling between $24 \mathrm{~h}$ and $72 \mathrm{~h}$ after cell seeding (Fig. 1a). Flow cytometry analysis confirmed that $\alpha_{\mathrm{v}} \beta_{3}$ integrin cell surface expression also increased with time (Fig. 1b). This 
a
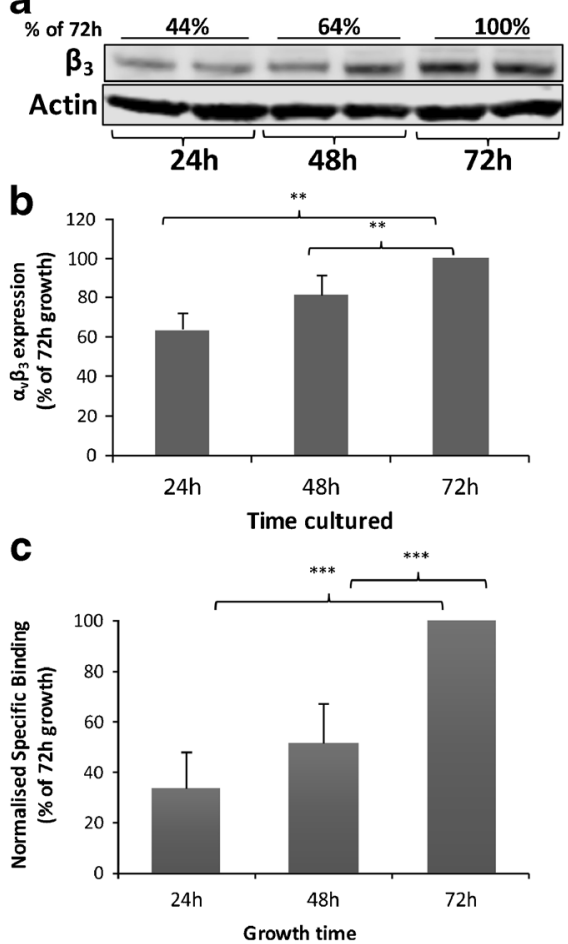

d $\beta_{3}$ knock-down in U87MG cell clones

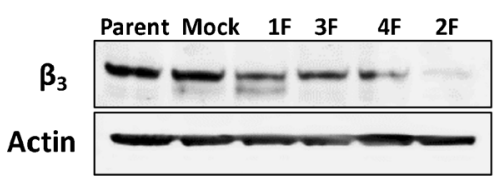

e
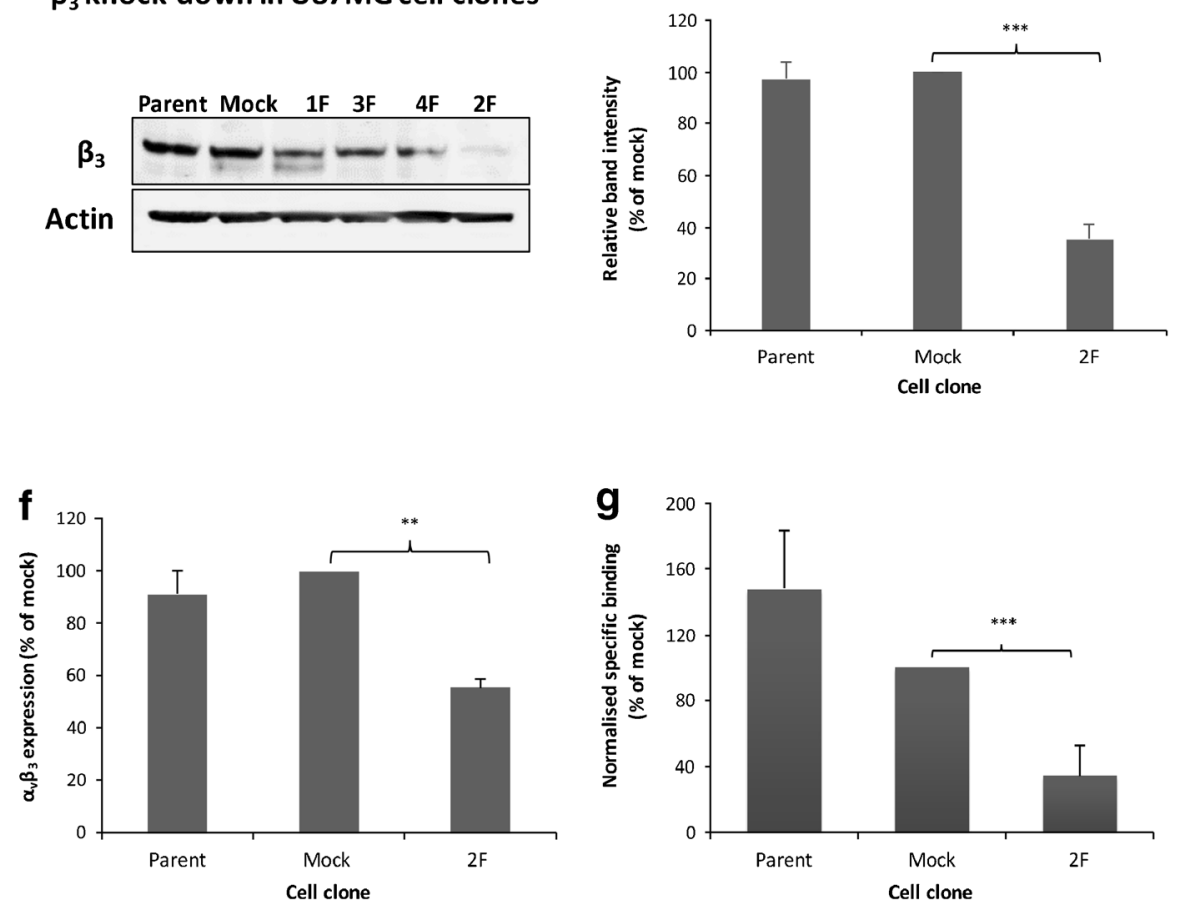

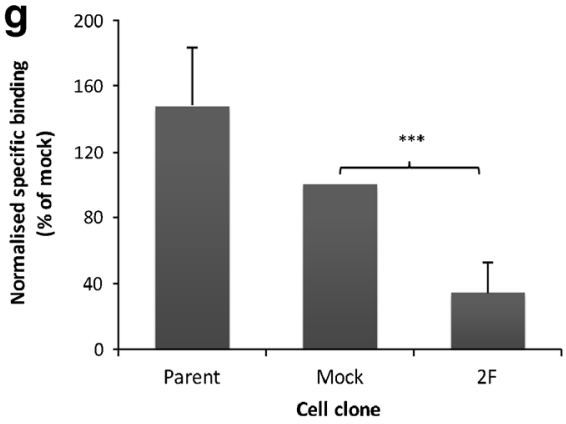

Fig. 1. $\alpha_{v} \beta_{3}$ integrin radiotracer binding reflects $\alpha_{v} \beta_{3}$ integrin expression. U87MG cells were grown for 24,48 or $72 \mathrm{~h}$ prior to analysis $(\mathbf{a}-\mathbf{c})$. a Representative $\beta_{3}$ integrin western blot with band quantification values stated. $\mathbf{b}$ Cell surface $\alpha_{\mathrm{v}} \beta_{3}$ expression by flow cytometry. $\mathbf{c}\left[{ }^{3} \mathrm{H}\right] Z \mathrm{ZMPZAT71}$ radiotracer binding assay. $\mathbf{d}-\mathbf{g}$ Analysis of U87MG cells with different $\beta_{3}$ integrin levels (untransfected parent, mock transfected and $2 \mathrm{~F} \beta_{3}$ integrin knock-down). $\mathbf{d}$ Representative and $\mathbf{e}$ quantified $\beta_{3}$ integrin western blot. $\mathbf{f}$ Cell surface $\alpha_{v} \beta_{3}$ expression by flow cytometry. $\mathbf{g}\left[{ }^{3} \mathrm{H}\right]$ ZMPZAT71 radiotracer binding assay. Results are representative or mean ( \pm SD) of at least three independent experiments. Statistical analysis: ${ }^{\star} P<0.05,{ }^{\star *} P<0.01$, ${ }^{\star \star \star} P<0.001$.

trait was used initially to investigate the ability of $\left[{ }^{3} \mathrm{H}\right]$ ZMPZAT71 to differentiate between different $\alpha_{v} \beta_{3}$ integrin expression levels. There was a clear timedependent increase in specific radiotracer binding (Fig. 1c), reflecting the increased integrin expression (Fig. 1a, b).

$\alpha_{v} \beta_{3}$ knock-down clones were developed to confirm that the radiotracer binds specifically to $\alpha_{v} \beta_{3}$ integrin. Since $\beta_{3}$ integrin forms heterodimers only with $\alpha_{\mathrm{v}}$ or $\alpha_{\mathrm{IIb}}$ [6], and cancer cells do not express $\alpha_{\mathrm{II}}, \alpha_{v} \beta_{3}$ knock-down clones can be generated by downregulating $\beta_{3}$ expression. Screening of multiple clones identified clone $2 \mathrm{~F}$, which exhibited a $65 \%$ reduction in $\beta_{3}$ integrin (Fig. 1d, e) and a $44 \%$ decrease in cell surface $\alpha_{v} \beta_{3}$ integrin expression (Fig. 1f). Radiotracer binding decreased by $66 \%$ in the $2 \mathrm{~F}$ clones (Fig. 1g), in line with the flow cytometry and western blotting results (Fig. 1e, f). These data confirm that downregulation of $\alpha_{v} \beta_{3}$ integrin produces a corresponding decrease in radiotracer binding. Overall, a good correlation $\left(r^{2}=0.91\right)$ was observed between radiotracer binding and $\alpha_{v} \beta_{3}$ integrin expression (Fig. S2).

\section{Radiotracer Binding Is Influenced by $\alpha_{v} \beta_{3}$ Activation Status}

It is well established that integrins are activated by $\mathrm{Mn}^{2+}$, minimally affected by $\mathrm{Mg}^{2+}$ and inhibited by $\mathrm{Ca}^{2+}[23]$.
Therefore, the effect of divalent cations on radiotracer binding was investigated to determine if the activation status of the receptor can influence $\left[{ }^{3} \mathrm{H}\right]$ ZMPZAT71 binding. Divalent cations were added to medium just prior to radiotracer, ensuring that cells were not exposed to these stimuli for longer than $30 \mathrm{~min}$. Indeed, in the presence of $\mathrm{Mn}^{2+}$, radiotracer binding significantly increased in both PC3 and U87MG cell lines (Fig. 2a), despite there being no significant increase in cell surface $\alpha_{v} \beta_{3}$ expression (data not shown). In contrast, $\mathrm{Mg}^{2+}$ did not increase radiotracer binding to either cell line, whereas $\mathrm{Ca}^{2+}$ decreased binding in both cell lines (Fig. 2a).

U87MG and PC3 cells were transfected with THD-GFP construct, a specific activator of integrin proteins [24], to determine whether the observed increase in radiotracer binding (Fig. 2a) is specifically due to integrin activation. Optimal transfection was observed after $24 \mathrm{~h}$ in PC3 cells and $48 \mathrm{~h}$ in U87MG cells (Fig. S3). THD expression had no significant effect on $\beta_{3}$ integrin expression (Fig. 2b), although a small increase (33 and $8 \%$, respectively) in cell surface $\alpha_{v} \beta_{3}$ expression was observed in U87MG and PC3 cells (Fig. 2c). THD transfection produced a significant increase in radiotracer binding in both cell lines; a $156 \%$ increase was observed in U87MG and a $297 \%$ increase in PC3 (Fig. 2d). These data are consistent with the activation effect observed with $\mathrm{Mn}^{2+}$. Together, these two datasets provide strong evidence that the activation status of $\alpha_{\mathrm{v}} \beta_{3}$ 

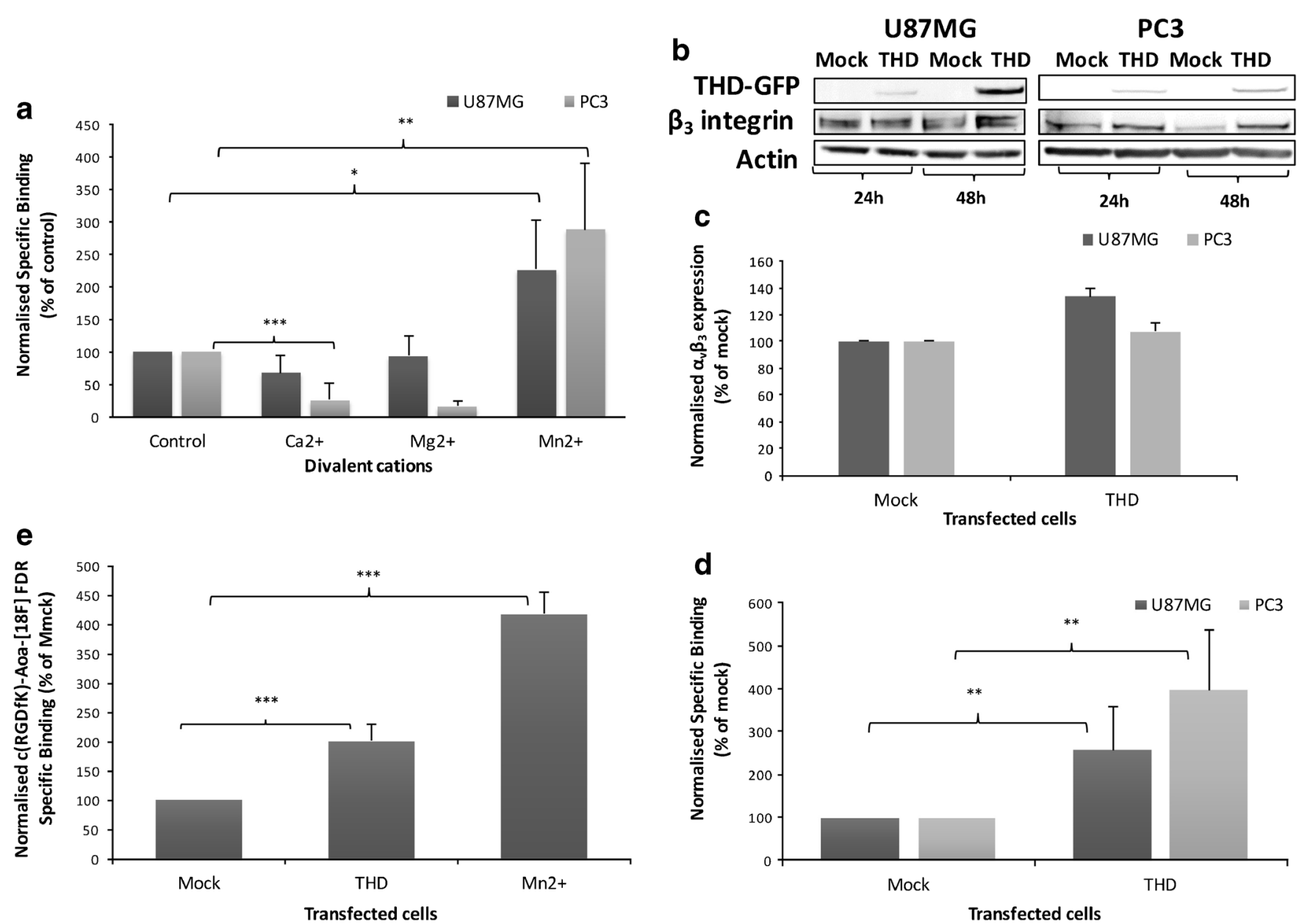

Fig. 2. $\alpha_{v} \beta_{3}$ integrin radiotracer binding is increased by receptor activation. a $\left[{ }^{3} \mathrm{H}\right] \mathrm{ZMPZAT71}$ radiotracer binding assay in the absence of metal ions (control) or in the presence of $1 \mathrm{mM} \mathrm{Mn}^{2+}, \mathrm{Mg}^{2+}$ or $\mathrm{Ca}^{2+}$. b-e Cells were either mock transfected or transfected with talin head domain (THD) linked to green fluorescent protein (GFP). $\mathbf{b}$ Western blot of $\beta_{3}$ integrin and THD expression. c Cell surface expression of $\alpha_{v} \beta_{3}$ by flow cytometry. d $\left[{ }^{3} \mathrm{H}\right] Z$ ZMPZAT71 and e $\left[{ }^{18} \mathrm{~F}\right] \mathrm{FDR}-\mathrm{Aoa}-\mathrm{C}(\mathrm{RGDfK})$ radiotracer binding assays. Results are representative or mean ( \pm SD) of at least three independent experiments. Statistical analysis: ${ }^{\star} P<0.05,{ }^{\star \star} P<0.01,{ }^{\star \star \star} P<0.001$.

integrin has a significant influence on $\left[{ }^{3} \mathrm{H}\right] \mathrm{ZMPZAT71}$ binding. An equivalent experiment was therefore performed with $\left[{ }^{18}\right.$ F]FDR-Aoa-c(RGDfK) [21] to ascertain whether binding of RGD-based radiotracers is similarly influenced by integrin activation. Indeed, the results clearly show that THD transfection and $\mathrm{Mn}^{2+}$ both significantly increased specific binding (Fig. 2e) of this class of radiotracers. Correlation $\left(r^{2}=0.83\right)$ was observed between radiotracer binding and $\alpha_{v} \beta_{3}$ integrin activation status (Fig. S2).

\section{Increased Cell Surface Integrin Expression Does Not Necessarily Enhance $\alpha_{v} \beta_{3}$ Integrin Radiotracer Binding}

$\alpha_{v} \beta_{3}$ integrin modulates signals from outside and inside cells. However, the impact of many signalling pathways on $\alpha_{v} \beta_{3}$ activation is uncertain [25]. UO126, a potent and selective MEK1/2 inhibitor, was used to study the effect of this signalling pathway on $\alpha_{v} \beta_{3}$ integrin. UO126 decreased ERK $1 / 2$ phosphorylation by approximately $90 \%$ in U87MG cells and resulted in both de-phosphorylation and degradation of ERK in PC3 cells (Fig. 3a, b). While UO126 had no significant effect on $\beta_{3}$ expression (Fig. 3b), $\alpha_{v} \beta_{3}$ cell surface expression significantly increased by $90 \%$ in U87MG and $175 \%$ in PC3 cells (Fig. 3c).

Radiotracer binding assays performed in the absence of $\mathrm{Mn}^{2+}$ detected an $82 \%$ increase in binding in U87MG cells and a $42 \%$ increase in PC3 cells after UO126 treatment (Fig. 3d). As expected (Fig. 2a), inclusion of $\mathrm{Mn}^{2+}$ increased radiotracer binding by 4.58 - and 3.7-fold in UO126-treated U87MG and PC3 cells, respectively (Fig. 3d). These results demonstrate that an increase in cell surface $\alpha_{\mathrm{v}} \beta_{3}$ expression does not necessarily produce an equivalent increase in radiotracer binding, but this can occur if the integrin becomes activated. These data also indicate that $\alpha_{v} \beta_{3}$ integrin radiotracers can report on the activation status of the receptor and that this is decreased by MEK $1 / 2$ inhibition. 
a

U87MG

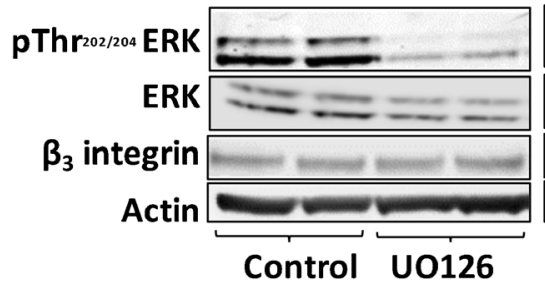

PC3

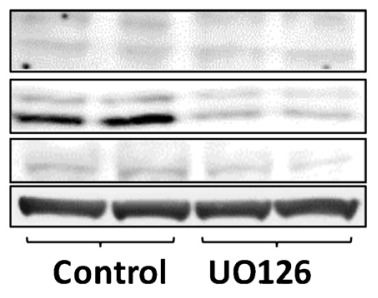

b

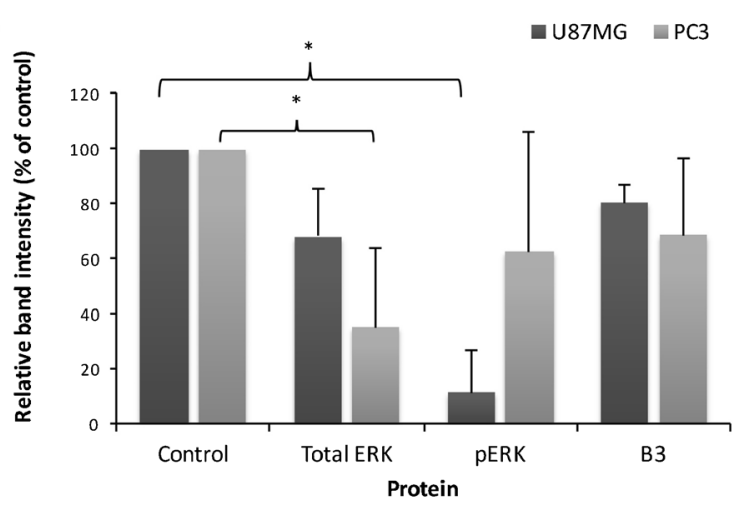

C

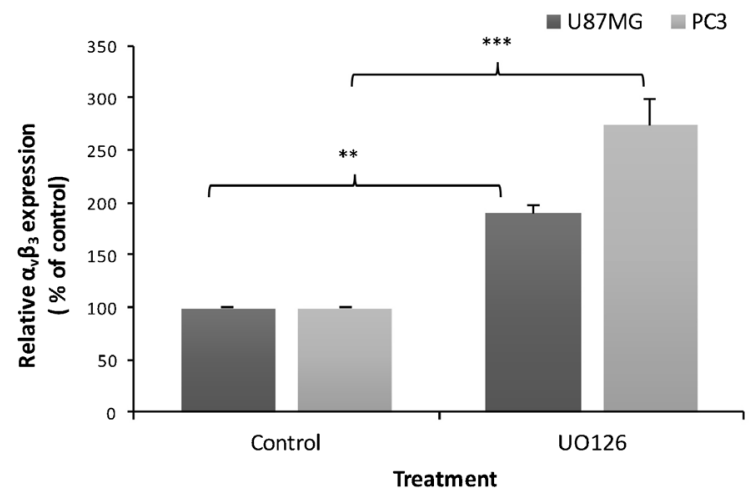

d

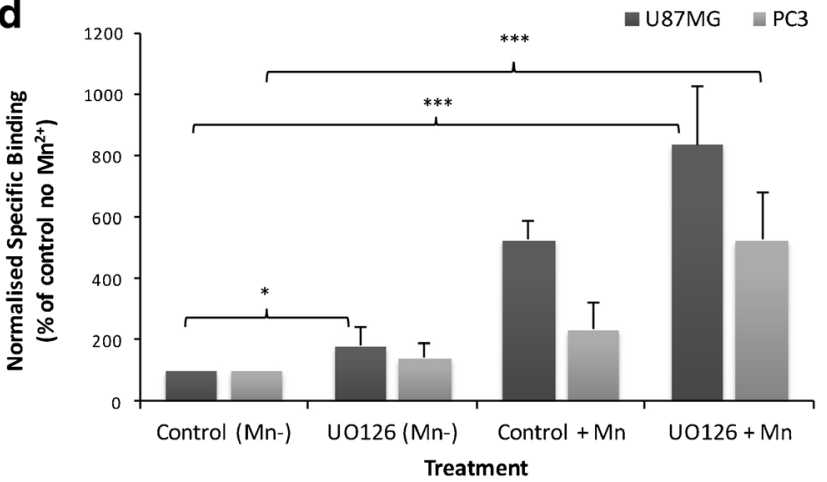

Fig. 3. ERK inhibition increases cell surface expression of $\alpha_{v} \beta_{3}$ but decreases its activation status. Cells were treated with $25 \mu \mathrm{M} \cup 0126$ or vehicle for $24 \mathrm{~h}$. a Representative and $\mathbf{b}$ quantitative western blots analysis of ERK, pERK and $\beta_{3}$ integrin. $\mathbf{c}$ Cell surface $\alpha_{v} \beta_{3}$ expression by flow cytometry. $\mathbf{d}\left[{ }^{3} \mathrm{H}\right] \mathrm{ZMPZAT71}$ radiotracer binding assay performed in the presence $(+)$ and absence $(-)$ of $\mathrm{Mn}^{2+}$. Results are representative or mean $( \pm \mathrm{SD})$ of at least three independent experiments. Statistical analysis: ${ }^{\star} P<0.05,{ }^{\star \star} P<0.01,{ }^{\star \star \star} P<0.001$.

\section{Modulation of $\alpha_{v} \beta_{3}$ Integrin with Pharmacological Inhibitors}

In light of the finding that $\alpha_{v} \beta_{3}$ integrin radiotracers can convey information on the activation status of its target receptor, we investigated how select kinases involved in $\alpha_{v} \beta_{3}$ signalling could modulate its activation status. Clustering of $\beta_{3}$ integrins induces activation of Src via phosphorylation of Tyr ${ }^{418}$ [26], stimulating tumour growth and lymph node metastases [27]. The influence of Src was tested using PP2, a selective Src inhibitor (Fig. S4). PP2 induced a $45 \%$ decrease in Src phosphorylation in both cell lines (Fig. 4a, b). Negligible changes were observed in $\beta_{3}$ integrin levels (Fig. 4b) or cell surface $\alpha_{v} \beta_{3}$ integrin expression (Fig. 4c). Radiotracer binding decreased by approximately $70 \%$ in PC3 and $40 \%$ in U87MG cells (Fig. 4d), suggesting that Src inhibition decreases $\alpha_{\mathrm{v}} \beta_{3}$ integrin activation. In contrast, inhibition of FAK phosphorylation using PF573228 had no significant effect on $\alpha_{v} \beta_{3}$ integrin expression, localisation or radiotracer binding (Fig. S5).

$\alpha_{v} \beta_{3}$ integrin activation is dependent on VEGFR2 in endothelial cells [28]. ZM323881, a potent and selective VEGFR2 inhibitor, was used to investigate the role of this receptor on $\alpha_{\mathrm{v}} \beta_{3}$ integrin expression and activation. ZM323881 treatment decreased $\mathrm{pTyr}^{1175}$ VEGFR2 by
$50 \%$ in PC3 but had no significant effect in U87MG cells, likely due to the lower baseline VEGFR2 phosphorylation level detected. No significant changes in $\beta_{3}$ integrin expression (Fig. 5a, b) or $\alpha_{\mathrm{v}} \beta_{3}$ integrin expression (Fig. 5c) were observed in either cell line. A $40 \%$ decrease in radiotracer binding was observed in PC3 cells, but no significant change was detected in U87MG cells (Fig. 5d). Hence, downregulation of VEGFR2 signalling is clearly linked to decreased $\alpha_{v} \beta_{3}$ integrin activation in cells. Importantly, inclusion of $\mathrm{Mn}^{2+}$ after cells had been treated with VEGFR2 (or Src) inhibitors significantly increased radiotracer binding (data not shown). This demonstrates that the receptor still retains the capacity to be activated and that the decreased radiotracer binding after drug treatment is due to reduced receptor activation status.

The understanding that $\alpha_{v} \beta_{3}$ integrin radiotracer binding is influenced by both receptor expression and activation is an important advance. Table 1 summarises the effect of each treatment used herein on integrin expression and activation. Expressing radiotracer binding as a function of cell surface $\alpha_{\mathrm{v}} \beta_{3}$ integrin expression produces a new metric that permits a direct comparison of the effect of diverse intracellular and extracellular treatments on $\alpha_{v} \beta_{3}$ integrin activation status.

Normalised $\alpha_{v} \beta_{3}$ integrin radiotracer binding after each treatment was expressed as a function of the normalised cell 
a
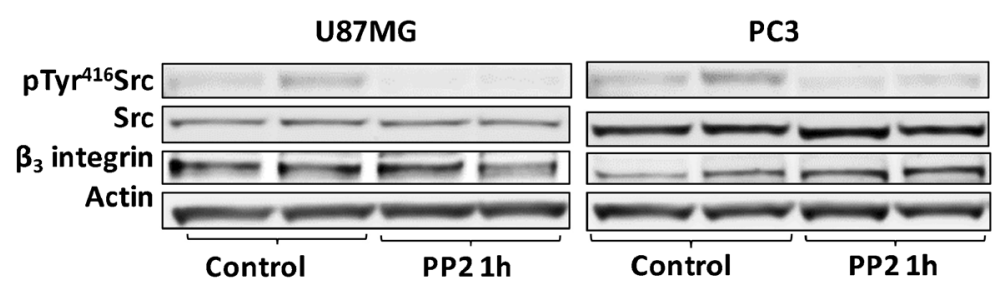

C

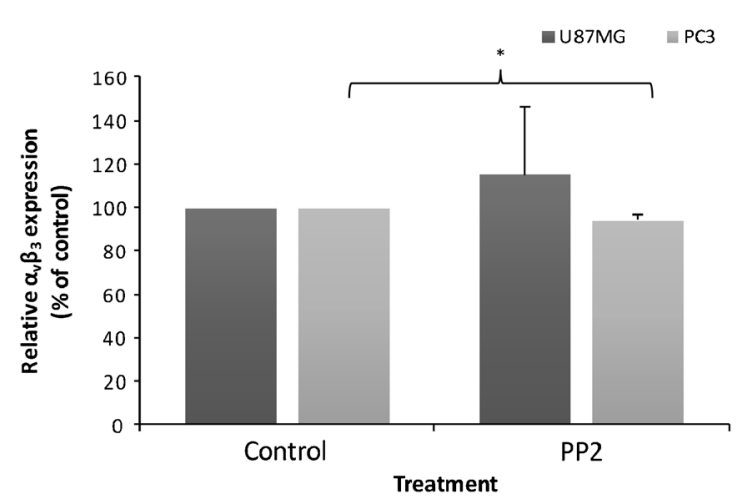

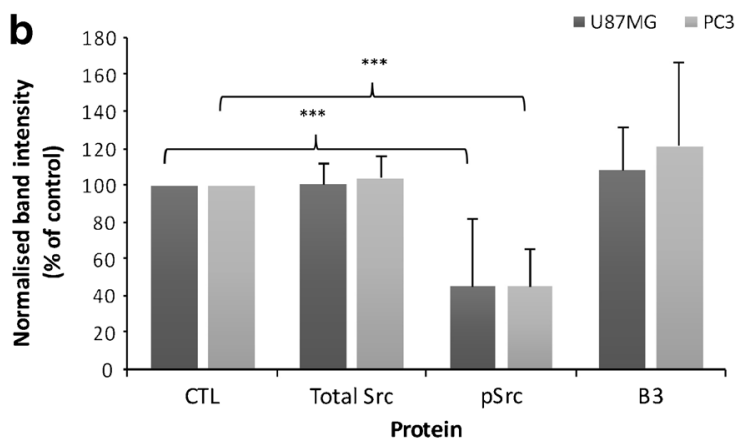

d

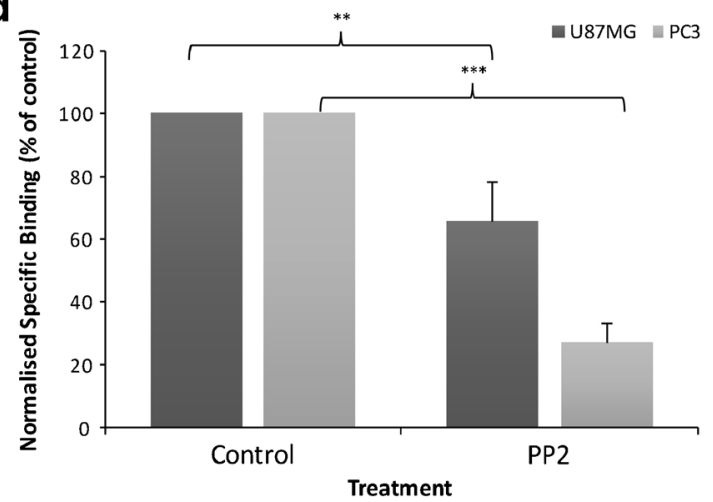

Fig. 4. Src inhibition decreases $\alpha_{v} \beta_{3}$ integrin radiotracer binding. Cells were treated with $10 \mu \mathrm{M}$ PP2 or vehicle for $1 \mathrm{~h}$. a Representative and $\mathbf{b}$ quantitative western blot analysis of Src, pSrc and $\beta_{3}$ integrin. $\mathbf{c}$ Cell surface $\alpha_{\mathrm{v}} \beta_{3}$ expression by flow cytometry. $\mathbf{d}\left[{ }^{3} \mathrm{H}\right] \mathrm{ZMPZAT71}$ radiotracer binding assay performed in the absence of $\mathrm{Mn}^{2+}$. Results are representative or mean $( \pm$ SD) of at least three independent experiments. Statistical analysis: ${ }^{*} P<0.05,{ }^{* \star} P<0.01,{ }^{* \star} P<0.001$.

surface $\alpha_{\mathrm{v}} \beta_{3}$ integrin expression. The resulting ratio provides a measure of $\alpha_{v} \beta_{3}$ integrin activation compared to control cells. A ratio $>1$ signifies activation, whereas a ratio $<1$ represents inhibition.

\section{Discussion}

There is an urgent need for sensitive, accurate and robust imaging methods to report on tumour angiogenesis since the current success rate of anti-angiogenic therapies varies considerably between both tumour types and individual patients. $\alpha_{v} \beta_{3}$ integrin is well recognised as an appropriate target for providing pertinent molecular imaging information, as the receptor is highly expressed on angiogenic endothelial cells and a validated target for assessing tumour angiogenesis [10]. Correlation between baseline $\alpha_{\mathrm{v}} \beta_{3}$ integrin expression and binding of $\alpha_{v} \beta_{3}$ integrin-targeted radiotracers has been established in multiple preclinical and clinical studies [11-15], demonstrating their suitability to detect tumours with angiogenic potential. On the other hand, while multiple preclinical studies have utilised $\alpha_{\mathrm{v}} \beta_{3}$ integrin radiotracers to assess response to anti-angiogenic therapies $[17,18,29-32]$, most have either consciously not reported correlation between radiotracer binding and receptor expression $[29,30,32]$ or have reported a lack of correlation [17, 18]. This strongly suggests that there are uncharacterised factor(s) that can influence radiotracer uptake in cells/ tumours. In this study, we directly demonstrate for the first time that radiotracer binding can be attributed to both $\alpha_{\mathrm{v}} \beta_{3}$ integrin activation status and expression, providing a rationale for the documented discrepancy between radiotracer binding and receptor expression after therapy.

Several lines of evidence demonstrate that $\left[{ }^{3} \mathrm{H}\right]$ ZMPZAT71 binds specifically to $\alpha_{v} \beta_{3}$ in cells and the magnitude of binding reflects receptor expression. Firstly, in U87MG cells, $\left[{ }^{3} \mathrm{H}\right]$ ZMPZAT71 binding increased in a temporal manner in parallel with $\alpha_{\mathrm{v}} \beta_{3}$ integrin (Fig. 1). Secondly, in $\beta_{3}$ integrin knock-down cells, proportionate decreases in radiotracer binding and receptor knock-down were observed (Fig. 1). Finally, UO126 treatment produced increases in both cell surface $\alpha_{v} \beta_{3}$ integrin expression and radiotracer binding when $\mathrm{Mn}^{2+}$ was present (Fig. 3). These results are in agreement with previous studies showing a direct relationship between $\alpha_{v} \beta_{3}$ integrin expression and a $\alpha_{v} \beta_{3}$-targeted radiotracer uptake in xenograft $[14,15]$ and clinical studies [11-13]. Taken together, these data provide strong evidence of a direct relationship between baseline receptor expression and binding of multiple distinct $\alpha_{v} \beta_{3}$ integrin radiotracers.

Significant increases in $\alpha_{v} \beta_{3}$ integrin radiotracer binding were observed in both cell line models after integrins were activated via two independent mechanisms (Fig. 2). $\mathrm{Mn}^{2+}$ 
a

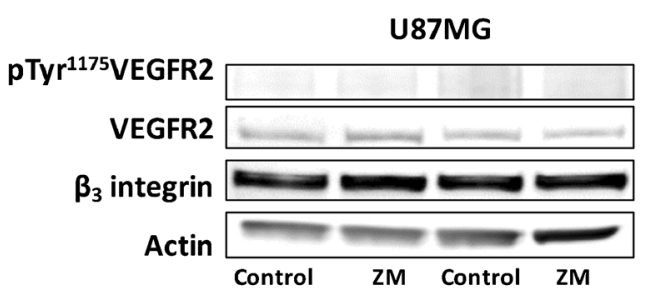

b

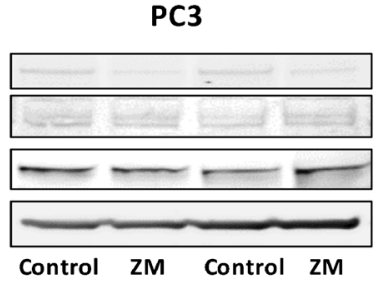

d

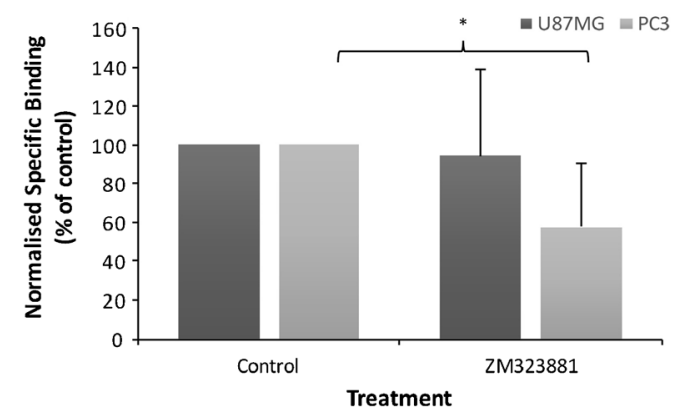

Fig. 5. VEGFR2 inhibition decreases $\alpha_{v} \beta_{3}$ integrin radiotracer binding. Cells were treated with $1 \mu M \mathrm{ZM} 323881$ for $1 \mathrm{~h}$ or vehicle for $1 \mathrm{~h}$. a Representative and $\mathbf{b}$ quantitative western blot analysis of VEGFR2, pVEGFR2 and $\beta_{3}$ integrin. $\mathbf{c}$ Cell surface $\alpha_{v} \beta_{3}$ expression by flow cytometry. $\mathbf{d}\left[{ }^{3} \mathrm{H}\right] Z \mathrm{ZMPZAT71}$ radiotracer binding assay performed in the absence of $\mathrm{Mn}^{2+}$. Results are representative or mean $\left( \pm S D\right.$ ) of at least three independent experiments. Statistical analysis: ${ }^{\star} P<0.05,{ }^{\star \star} P<0.01,{ }^{* \star \star} P<0.001$.

binds to metal ion-dependent adhesion site (MIDAS) on the $\beta$ subunit extracellular domain [7], producing a conformation change that increases $\alpha_{\mathrm{v}} \beta_{3}$ affinity/avidity for ligands [33]. The opposite effect was observed with $\mathrm{Ca}^{2+}$, confirming that integrin activity can also be decreased. Talin head domain selectively activates integrins by binding to their intracellular domain and changing their conformation [34]. The data presented herein indicate that radiotracer binding is sensitive to integrin activation induced either by extracellular or intracellular activation. Indeed, this is apparently a class effect since binding of two distinct $\alpha_{v} \beta_{3}$ integrin binding radiotracers, $\left[{ }^{3} \mathrm{H}\right]$ ZMPZAT71 and $\left[{ }^{18}\right.$ F]FDR-Aoa-(RGDfK), was enhanced. Taken together, these two datasets provide very strong evidence that radiotracer binding is sensitive to integrin activation status in cells and that these radiotracers can report on $\alpha_{v} \beta_{3}$ integrin activation status. To our knowledge, this is the first study to directly demonstrate this.

Two xenograft studies have also reported changes in binding of $\alpha_{v} \beta_{3}$ integrin radiotracers that cannot be accounted for by altered $\alpha_{v} \beta_{3}$ integrin expression [17, 18]. The most likely interpretation of the study data is that $\alpha_{v} \beta_{3}$ integrin activation is also modulated in vivo. In the first study, an U87MG xenograft was treated with the Src inhibitor dasatinib. $\left[{ }^{64} \mathrm{Cu}\right]-\mathrm{DOTA}-\mathrm{c}(\mathrm{RGDfK})$ radiotracer uptake was decreased in the absence of any effect on total or cell surface $\alpha_{v} \beta_{3}$ integrin expression [18]. This result can be accounted for by the decrease in $\alpha_{\mathrm{v}} \beta_{3}$ integrin activation caused by Src inhibitors (Fig. $4 \mathrm{~d}$ and Table 1). The second study involved an A431 xenograft treated with bevacizumab.

Table 1. Expressing $\alpha_{v} \beta_{3}$ integrin radiotracer binding as a function of cell surface expression produces a measure of integrin activation

\begin{tabular}{|c|c|c|c|c|c|c|c|}
\hline \multirow[b]{2}{*}{ Cell line } & \multicolumn{2}{|c|}{$\begin{array}{l}\text { Relative } \\
\alpha_{\mathrm{v}} \beta_{3} \text { expression }\end{array}$} & \multicolumn{2}{|c|}{$\begin{array}{l}\text { Relative radiotracer } \\
\text { binding }\end{array}$} & \multicolumn{2}{|c|}{$\begin{array}{l}\text { Activation ratio } \\
\text { (binding/expression) }\end{array}$} & \multirow{2}{*}{$\begin{array}{l}\text { Effect on } \\
\alpha_{\mathbf{v}} \beta_{3} \text { activity } \\
-\end{array}$} \\
\hline & PC3 & U87MG & PC3 & U87MG & PC3 & U87MG & \\
\hline \multicolumn{8}{|l|}{ Treatment } \\
\hline Control & 100 & 100 & 100 & 100 & 1.00 & 1.00 & - \\
\hline $\mathrm{Mn}^{2+}$ & 100 & 100 & 288 & 227 & 2.88 & 2.27 & Activation \\
\hline THD & 108 & 133 & 397 & 256 & 3.68 & 1.92 & Activation \\
\hline UO126 & 274 & 190 & 142 & 182 & 0.52 & 0.95 & Inhibition \\
\hline $\mathrm{UO} 126+\mathrm{Mn}^{2+}$ & 274 & 190 & 526 & 834 & 1.92 & 4.39 & Activation \\
\hline PP2 & 92 & 115 & 27 & 66 & 0.29 & 0.57 & Inhibition \\
\hline PF573228 & 102 & 114 & 124 & 102 & 1.22 & 0.89 & No apparent change \\
\hline ZM323881 & 99 & 110 & 58 & 95 & 0.59 & 0.86 & Inhibition in PC3 cells \\
\hline
\end{tabular}

Bold text has been used to represent increased radiotracer binding and italic text to highlight decreased radiotracer binding 
Increased $\left[{ }^{68} \mathrm{Ga}\right]-N O D A G A-c(R G D f K)$ binding was observed despite a $50 \%$ decrease in $\alpha_{\mathrm{v}} \beta_{3}$ integrin expression [17]. The authors attributed the increased binding to integrin activation and/or enhanced tumour perfusion. On the other hand, an MDA-MB-435 xenograft study showed that $\left[{ }^{18} \mathrm{~F}\right]$ FPPRGD2 binding and $\alpha_{\mathrm{v}} \beta_{3}$ integrin staining both decreased after treatment with ZD4190, a potent inhibitor of VEGFR1 and VEGFR2 inhibitor [31], in agreement with the observed correlation between baseline integrin expression and radiotracer binding (Fig. 1) [11, 12, 14, 15]. Other in vivo studies have not assessed $\alpha_{\mathrm{v}} \beta_{3}$ integrin expression $[29,30,32]$ but have demonstrated decreased radiotracer binding after treatment with VEGFR2 inhibitors. In light of the data presented in Fig. 5, it seems likely that the observed decrease in radiotracer binding could be attributed to decreased $\alpha_{v} \beta_{3}$ integrin activation.

Prior to this study, the effect of individual cell signalling proteins on $\alpha_{\mathrm{v}} \beta_{3}$ integrin activation was not clear $[4,25]$. Our finding that $\alpha_{v} \beta_{3}$ integrin binding radiotracers can report on $\alpha_{\mathrm{v}} \beta_{3}$ integrin activation status allows this otherwise inaccessible information to be directly revealed. The results clearly demonstrate that inhibition of MEK1/2, Src and VEGFR2, but not FAK, decreases $\alpha_{\mathrm{v}} \beta_{3}$ integrin activation (Table 1). The effect of the Src inhibitor is in line with a U87MG xenograft study that intimates that the Src inhibitor dasatinib may decrease $\alpha_{\mathrm{v}} \beta_{3}$ integrin activation [18]. It is well established that Src family kinases are activated by integrins through the $\beta_{3}$ cytoplasmic tail. The data presented herein demonstrate that $\mathrm{Src}$ also plays a role in integrin activation, although it is not clear if this is a direct or indirect effect. The inhibitory effect of VEGFR2 inhibitors shown here (Fig. 5) provides a molecular rationale for several xenograft studies that have shown reduced radiotracer uptake [30-32] after VEGFR2 inhibitor treatment. VEGFR2- $\alpha_{v} \beta_{3}$ integrin association is important for full VEGFR2 activity and subsequent activation of intracellular signalling pathways [2]. As VEGFR2 autophosphorylation is crucial for VEGFR2- $\alpha_{v} \beta_{3}$ interaction, VEGFR2 inhibitors can reduce $\alpha_{v} \beta_{3}$ integrin activation. The magnitude of this effect appears to be dependent on the basal level of VEGFR2 phosphorylation, since an inhibitory effect was not observed in U87MG cells, which contain lower levels of VEGFR2 phosphorylation. Increased cell surface expression of $\alpha_{v} \beta_{3}$ and other integrin subunits following UO126 treatment have been reported previously $[35,36]$. However, its inhibitory effect on $\alpha_{v} \beta_{3}$ integrin activation has not been documented. One possibility is that the increased cell surface expression of $\alpha_{v} \beta_{3}$ integrin is a direct consequence of the decreased integrin activity.

The data reported herein have significant implications for assessing response to anti-angiogenic therapies in clinical studies. Studies need to consider both the expression level and activation status of integrins. This will make data interpretation more challenging but also raises new possibilities. Challenges include the confounding factors arising from combining anti-angiogenics with standard chemotherapies, which could either alter the expression level or activation status of $\alpha_{\mathrm{v}} \beta_{3}$ integrin. Opportunities include the possibility of studying binding of $\alpha_{v} \beta_{3}$ integrin radiotracers to either the tumour vasculature or tumour cells that express $\alpha_{v} \beta_{3}$ integrin, to assess the efficacy of Src, VEGFR2 and MEK inhibitors. This study provides valuable insight into the molecular mechanism of modulation of integrin signalling pathways in response to anti-cancer agents, but further work is required to take full advantage of these new opportunities to use $\alpha_{\mathrm{v}} \beta_{3}$ integrin-targeted radiotracers for assessing response to therapy.

\section{Conclusion}

Binding of radiotracers to cells corresponds with both changes in $\alpha_{v} \beta_{3}$ integrin expression and activation status. These results are applicable to both RGD-labelled peptides and small molecule antagonists of $\alpha_{\mathrm{v}} \beta_{3}$ integrin, indicating that this is a general effect, pertinent to this entire class of radiotracers. These findings provide a rationale for the documented discrepancy between radiotracer binding and receptor expression after therapy in several xenograft studies and have important consequences for imaging $\alpha_{\mathrm{v}} \beta_{3}$ integrin in vivo. Some tumours that express this receptor may not have significant uptake of these radiotracers if the receptors are not activated. Moreover, these radiotracers appear to have significant potential to assess response to treatment with a range of classes of anti-cancer drugs (e.g., ERK, Src and VEGFR2 inhibitors) by providing early guidance on the efficacy of these agents in clinical studies.

Acknowledgements. We are very grateful to Prof. Calderwood (Yale University, USA) for providing the THD DNA construct, Dr. Massimiliano Baldassarre (University of Aberdeen) for useful discussions on integrin regulation and Charlie Taylor for helping to optimise the THD transfection experiments. We thank the NHS Grampian Endowment Fund for funding this research and CRANES and the Roland Sutton Academic Trust for financial support for AA.

Authors' Contribution. INF and AA conceived and designed the experiments. AA performed the majority of the experiments. INF and AA analysed the data. SD designed and synthesised $\left[{ }^{18} \mathrm{~F}\right] \mathrm{FDR}-\mathrm{Aoa}-\mathrm{c}(\mathrm{RGDfK})$ radiotracer. MP designed and synthesised the cold ZMPZAT71 compound. JC generated the $\beta_{3}$ knock-down cells. AA prepared the first draft of the manuscript. INF and MZ edited the manuscript. All authors read and approved the final manuscript.

\section{Compliance with Ethical Standards}

\section{Conflict of Interest}

The authors declare that they have no conflicts of interest.

Open Access This article is distributed under the terms of the Creative Commons Attribution 4.0 International License (http:// creativecommons.org/licenses/by/4.0/), which permits unrestricted use, distribution, and reproduction in any medium, provided you give appropriate credit to the original author(s) and the source, provide a link to the Creative Commons license, and indicate if changes were made. 


\section{References}

1. Carmeliet P, Jain RK (2000) Angiogenesis in cancer and other diseases. Nature 407:249-257

2. Mahabeleshwar GH, Feng W, Phillips DR, Byzova TV (2006) Integrin signaling is critical for pathological angiogenesis. J Exp Med 203:2495-2507

3. Somanath PR, Malinin NL, Byzova TV (2009) Cooperation between integrin $\alpha_{\mathrm{v}} \beta_{3}$ and VEGFR2 in angiogenesis. Angiogenesis 12:177185

4. Campbell ID, Humphries MJ (2011) Integrin structure, activation, and interactions. Cold Spring Harb Perspect Biol 3

5. Xiong J, Stehle T, Diefenbach B et al (2001) Crystal structure of the extracellular segment of integrin $\alpha_{v} \beta_{3}$. Science 294:339-345

6. Hynes RO (2002) Integrins: bidirectional, allosteric signaling machines. Cell 110:673-687

7. Takagi J, Petre BM, Walz T, Springer TA (2002) Global conformational rearrangements in integrin extracellular domains in outside-in and inside-out signaling. Cell 110:599-611

8. Backer MVBJ (2012) Imaging key biomarkers of tumor angiogenesis. Theranostics 2:502-515

9. Gladson CL (1996) Expression of integrin $\alpha_{\mathrm{v}} \beta_{3}$ integrin in small blood vessels of glioblastoma tumors. J Neuropathol Exp Neurol 55

10. Brooks PC, Montgomery AMP, Rosenfeld M et al (1994) Integrin $\alpha_{v} \beta_{3}$ antagonists promote tumor regression by inducing apoptosis of angiogenic blood vessels. Cell 79:1157-1164

11. Beer AJ, Haubner R, Sarbia M et al (2006) Positron emission tomography using $\left[{ }^{18} \mathrm{~F}\right]$ Galacto-RGD identifies the level of integrin $\alpha_{\mathrm{v}} \beta_{3}$ expression in man. Clin Cancer Res 12:3942-3949

12. Mena E, Owenius R, Turkbey B et al (2014) $\left[{ }^{18} \mathrm{~F}\right]$ Fluciclatide in the in vivo evaluation of human melanoma and renal tumors expressing $\alpha_{\mathrm{v}} \beta_{3}$ and $\alpha_{\mathrm{v}} \beta_{5}$ integrins. Eur J Nucl Med Mol Imaging 41:1879-1888

13. Schnell O, Krebs B, Carlsen J et al (2009) Imaging of integrin avß3 expression in patients with malignant glioma by $\left[{ }^{18} \mathrm{~F}\right]$ Galacto-RGD positron emission tomography. Neuro-Oncology 11:861-870

14. Alam IS, Witney T, Tomasi G et al (2014) Radiolabeled RGD tracer kinetics annotates differential $\alpha_{\mathrm{v}} \beta_{3}$ integrin expression linked to cell intrinsic and vessel expression. Mol Imaging Biol 16:558-566

15. Haubner R, Weber WA, Beer AJ et al (2005) Noninvasive visualization of the activated $\alpha_{v} \beta_{3}$ integrin in cancer patients by positron emission tomography and $\left[{ }^{18} \mathrm{~F}\right]$ Galacto-RGD. PLoS Med 2:e70

16. Niu G, Chen $\mathrm{X}$ (2011) Why integrin as a primary target for imaging and therapy. Theranostics 1:30-47

17. Rylova SN, Barnucz E, Fani M et al (2014) Does imaging $\alpha_{\mathrm{v}} \beta_{3}$ integrin expression with PET detect changes in angiogenesis during bevacizumab therapy? J Nucl Med 55:1878-1884

18. Dumont RA, Hildebrandt I, Su H et al (2009) Noninvasive imaging of aVB3 function as a predictor of the antimigratory and antiproliferative effects of dasatinib. Cancer Res 69:3173-3179

19. Bouaouina M, Lad Y, Calderwood DA (2008) The N-terminal domains of talin cooperate with the phosphotyrosine binding-like domain to activate $\beta 1$ and $\beta 3$ integrins. J Biol Chem 283:6118-6125
20. Green SR, Choudhary AK, Fleming IN (2010) Combination of sapacitabine and HDAC inhibitors stimulates cell death in AML and other tumour types. Br J Cancer 103:1391-1399

21. Dall'Angelo S, Zhang Q, Fleming IN et al (2013) Efficient bioconjugation of 5-fluoro-5-deoxy-ribose (FDR) to RGD peptides for positron emission tomography (PET) imaging of $\alpha_{\mathrm{v}} \beta_{3}$ integrin receptor. Org Biomol Chem 11:4551-4558

22. Piras M, Testa A, Fleming IN et al (2017) High affinity "click" RGD peptidomimetics as radiolabelled probes for imaging $\alpha_{\mathrm{v}} \beta_{3}$ integrin. ChemMedChem. doi:10.1002/cmdc.201700328

23. Elices MJ, Urry LA, Hemler ME (1991) Receptor functions for the integrin VLA-3: fibronectin, collagen, and laminin binding are differentially influenced by Arg-Gly-Asp peptide and by divalent cations. JCell Biol 112:169

24. Calderwood DA, Zent R, Grant R et al (1999) The talin head domain binds to integrin $\beta$ subunit cytoplasmic tails and regulates integrin activation. J Biol Chem 274:28071-28074

25. Bouvard D, Pouwels J, De Franceschi N, Ivaska J (2013) Integrin inactivators: balancing cellular functions in vitro and in vivo. Nat Rev Mol Cell Biol 14:430-442

26. Arias-Salgado EG, Lizano S, Sarkar S et al (2003) Src kinase activation by direct interaction with the integrin $\beta$ cytoplasmic domain. Proc Nat Acad Sci 100:13298-13302

27. Desgrosellier JS, Barnes LA, Shields DJ et al (2009) Integrin $\alpha_{v} \beta_{3} / \mathrm{c}-$ Src 'oncogenic unit' promotes anchorage-independence and tumour progression. Nat Med 15:1163-1169

28. Mahabeleshwar GH, Chen J, Feng W et al (2008) Integrin affinity modulation in angiogenesis. Cell Cycle 7:335-347

29. Battle MR, Goggi JL, Allen L et al (2011) Monitoring tumor response to antiangiogenic sunitinib therapy with ${ }^{18} \mathrm{~F}$-fluciclatide, an ${ }^{18} \mathrm{~F}$ labeled $\alpha_{\mathrm{v}} \beta_{3}$-integrin and $\alpha_{\mathrm{v}} \beta_{5}$-integrin imaging agent. J Nucl Med 52:424-430

30. Morrison MS, Ricketts S, Barnett J et al (2009) Use of a novel ArgGly-Asp radioligand, ${ }^{18} \mathrm{~F}$-AH111585, to determine changes in tumor vascularity after antitumor therapy. J Nucl Med 50:116-122

31. Yang M, Gao H, Yan Y et al (2011) PET imaging of early response to the tyrosine kinase inhibitor ZD4190. Eur J Nucl Med Mol Imaging 38:1237-1247

32. Goggi JL, Bejot R, Moonshi SS, Bhakoo KK (2013) Stratification of ${ }^{18} \mathrm{~F}$-labeled PET imaging agents for the assessment of antiangiogenic therapy responses in tumors. J Nucl Med 54:1630-1636

33. Plow EF, Haas TA, Zhang L et al (2000) Ligand binding to integrins. J Biol Chem 275:21785-21788

34. Calderwood DA, Campbell ID, Critchley DR (2013) Talins and kindlins: partners in integrin-mediated adhesion. Nat Rev Mol Cell Biol 14:503-517

35. Vellon L, Menendez JA, Lupu R (2006) A bidirectional “ $\alpha_{\mathrm{v}} \beta_{3}$ integrin-ERK1/ERK2 MAPK" connection regulates the proliferation of breast cancer cells. Mol Carcinog 45:795-804

36. Neal CL, Mckeithen D, Odero-Marah V (2011) Snail negatively regulates cell adhesion to extracellular matrix and integrin expression via the MAPK pathway in prostate cancer cells. Cell Adhes Migr $5: 249-257$ 